\title{
Role of anticardiolipin antibodies in bad obstetric history detected by ELISA test in a tertiary care centre
}

\author{
Therese Mary Dhason $^{1 *}$, Euphrasia Latha Jairaj ${ }^{1}$, Rajeswari Sankaralingam ${ }^{1}$, Bhuvanesh \\ Mahendren $^{1}$, Balaji Chilukuri ${ }^{1}$, Sivakumar Vengudusamy ${ }^{1}$, Mythili Seetharaman ${ }^{1}$ \\ ${ }^{1}$ Institute of Rheumatology, Rajiv Gandhi Government General Hospital, \\ Madras Medical College, Tamil Nadu, India.
}

\begin{abstract}
Background: Antiphospholipid syndrome (APS) is one of the causes of recurrent abortions and intrauterine death among pregnant women. This study was undertaken to find out the association between bad obstetric history (BOH) and anticardiolipin (aCL) antibody.

Material and Methods: Blood samples were collected from women with BOH referred (recurrent abortion, intrauterine death, PIH) to a Tertiary Care Center in Chennai, Tamil Nadu. Blood samples from 100 pregnant women with BOH and 110 healthy pregnant women were collected and tested for the presence of aCL antibody by ELISA Method.

Results: Among the 100 patients tested 21 (21\%) were aCL positive; IgG was positive in $16(76.19 \%)$ patients and IgM was positive in $5(23.80 \%)$ patients. Anticordiolipin antibody (aCL) positivity in $\mathrm{BOH}$ was statistically significant (p .0048) when compared to healthy pregnant women. There was a positive correlation ( $\mathrm{p} 0.005)$ between IgG and BOH. The antibody titer was high in $12(57.14 \%)$ and moderate in $6(28.57 \%)$. Among the controls $8(7.2 \%)$ were aCL positive. Conclusion: Screening of patients with BOH for aCL by ELISA will reduce foetal morbidity and mortality as there is a significant association between high, moderate titers of $\mathrm{aCL}$, (IgG) and BOH.
\end{abstract}

Key words: Antiphospholipid syndrome, Anticordiolipin Elisa, Bad Obstetric History.

\section{Introduction}

The systemic autoimmune disorder which causes recurrent vascular thrombosis and pregnancy losses is antiphospholipid syndrome (APS). The pathogenesis of APS is production of auto antibodies to phospholipid protein. The diagnosis is based on clinical and laboratory criteria. The diagnostic markerswhich clinch the diagnosis of APS are persistent rise in antiphospholipid antibodies and lupus anticoagulant positivity (1). Antiphospholipid syndrome may be either primary or secondary. When APS is present in patients without any underlying clinical illness it is primary. Secondary APS occurs in patientswith systemic lupus erythematosus (SLE) or any other underlying autoimmune disease.

*Corresponding Author: Therese Mary Dhason, Senior Assistant Professor of Microbiology (Immunology) Institute of Rheumatology Rajiv Gandhi Govt. General Hospital Madras Medical College E.V.R.Periyar Road, Chennai-600003, TamilNadu India. E-mail: tmary1964@gmail.com Received: Feb 25, 2017 Accepted: Jul 07, 2017
The autoantibodies are present in $50 \%$ of patients with SLE and $1-5 \%$ of the general population. The antiphospholipid antibodies are found in serum in $1 \%$ of healthy persons and $3 \%$ of older age group (2). Though APS can involve any age group, the target group is young to middle aged adults.

Depending upon the site of vascular obstruction, various symptoms occur in patients with APS. Interference in the balance between procoagulant and anticoagulant factors and disruption of the clotting mechanism by the antiphospholipid antibodies (APLA) lead to leg ulcers, toe gangrene, myocardial infarction, purpura, stroke, recurrent miscarriage or preterm births.

This is an Open Access article distributed under the terms of the Creative Commons Attribution Non-Commercial License (http://creativecommons.org/licenses/bync/4.0/) which permits unrestricted non-commercial use, distribution, and reproduction in any medium, provided the original work is properly cited. 
Pregnant women with bad obstetric history are screened for $\mathrm{Rh}$ incompatibility, TORCH infections, structural abnormalities in uterus and also for APS in Tertiary Care Centers. The pregnant women with $\mathrm{BOH}$ referred to immunology laboratory from various maternity hospitals were screened for the presence of aCL antibodies in our study.

Antiphospholipid syndrome is detected either by a positive anticardiolipin antibody (aCL) or lupus anticoagulant test (3). Anticardiolipin ELISA is the test done to detect the antiphospholipid antibodies. The test results are reported by the specific aCL isotype (IgG, $\operatorname{IgM}$, and $\operatorname{IgA}$ ) and their levels in serum. The unit for measuring the levels is the phospholipid (PL) unit and is denoted as GPL (G phospholipid) MPL (M phospholipid) or APL (A phospholipid). According to the Second International Anticardiolipin Standardization Workshop $<20$ PL is low positive, 20-80 $\mathrm{PL}$ is medium positive and $>80 \mathrm{PL}$ unit is high positive (4). Though a moderate to high aCL IgG is the most specific diagnostic marker in APS, some patients are only IgM positive and in few patients IgA aCL is the sole marker of disease (5).

According to the Revised Sapporo classification, APS is diagnosed when one of the clinical and laboratory criteria are met (6).

The appropriate management of pregnant women with APS, increase the fetal survival and delivery of a healthy infant in more than $70 \%$ of them. Though the treatment protocol has not been formulated by randomized trials in bad obstetric history, a combined therapy with aspirin and heparin has been suggested to improve the fetal outcome (7).

Antiphospholipid antibodies (APLA) has been attributed in the pathogenesis of APS in pregnant women with $\mathrm{BOH}$. Hence a study focused on anticardiolipin antibodies in bad obstetric history was undertaken at a Tertiary Care Center in Chennai so as to treat them effectively thereby preventing abortions and stillbirths.

\section{Materials and methods}

A cross sectional study was undertaken in a Tertiary Care Center at Chennai to find out the significance between anti cardiolipin antibodies and bad obstetric history. The study was conducted over a period of 1yr from January 2016 to December 2016. The study group included 100 pregnant women with $\mathrm{BOH}$ and 110 healthy pregnant women.
Blood samples were collected from 100 pregnant women with history of $\mathrm{BOH}$ and 110 pregnant women with normal course of pregnancy. Serum was separated and tested for the presence of aCL IgG and IgM using ELISA kits procured from Calbiotech (CA). All the samples and the kit reagents were brought to room temperature. Test samples were diluted with sample diluent in 1:21 dilution. In the first step, $100 \mu 1$ of calibrators, controls (PC and $\mathrm{NC}$ ) and diluted sera were added into the appropriate wells coated with bovine cardiolipin antigen. To the well 1A given as Blank $100 \mu \mathrm{l}$ of sample diluent was dispensed. The microtiter plate was incubated at room temperature for $20 \mathrm{mts}$. Wells were washed three times with $300 \mu 1$ of wash buffer. In the next step $100 \mu 1$ of enzyme conjugate (IgG) was dispensed in all the wells and incubated for 20mts. Wells were again washed three times with $300 \mu 1$ of wash buffer. Then $100 \mu 1$ of TMB (Tetra methyl benzidine) substrate was dispensed and incubated for $10 \mathrm{mts}$ at room temperature. Finally $100 \mu 1$ of stop solution was added to all the wells. Optical density (OD) of calibrators, controls (PC \& NC) and samples was read within 15 minutes in an ELISA Reader at $450 \mathrm{~nm}$ wavelength. The same procedure was done in parallel with IgM enzyme conjugate.

The test was considered valid if the OD of the calibrator was greater than 0.250 , negative control was less than 0.9 and positive control was greater than 1.2. Antibody index was converted to GPL units by multiplying antibody index value by 11 and MPL units by multiplying antibody index value by 17 .

\section{Inclusion criteria}

History of recurrent abortions at or more than 10 weeks. History of one or more premature births before 34 weeks of gestation due to placental insufficiency.

\section{Exclusion criteria}

Anemia complicating pregnancy, TORCH positive, other systemic diseases. TORCH positive. Other systemic diseases. Structural abnormalities of uterus.

\section{Statistical analysis}

The data were analyzed by SPSS package. Fishers $2 \times 2$ test was applied to analyze the significance of anticardiolipin antibodies in $\mathrm{BOH}$. Chi-square and Fisher-exact twotailed tests were used to find out the significance of isotypes $\mathrm{IgG}$ and $\mathrm{IgM}$ anticardiolipin antibodies in $\mathrm{BOH}$. 


\section{Results}

Out of the 100 pregnant women with $\mathrm{BOH}$ tested for aCL antibody, 21 (21\%) were positive. Among the 110 controls $8(7.2 \%)$ were aCL antibody positive.

Out of the 21 positive for aCL antibody $5(23.81 \%)$ were IgM positive and 16 (76.19\%) were IgG positive.

ELISA test for detection of anti-cardiolipin antibody is considered positive when the antibody index is above 1.1. The aCL antibody concentration was calculated based on the formula specified in the kit. The aCL positivity in pregnant women with $\mathrm{BOH}$ was compared with healthy controls (Table 1).

Table 1. aCL positivity in diseased versus controls.

\begin{tabular}{|c|c|c|c|c|}
\hline \multirow[t]{2}{*}{$\begin{array}{l}\text { Study } \\
\text { group }\end{array}$} & & $\begin{array}{c}\text { ACL } \\
\text { Positive }\end{array}$ & $\begin{array}{c}\text { ACL } \\
\text { Negative }\end{array}$ & p value \\
\hline & $\mathbf{n}$ & $\mathbf{n}$ & $\mathbf{n}$ & \\
\hline Diseased & 100 & 21 & 79 & 0.0048* \\
\hline $\begin{array}{l}\text { Healthy } \\
\text { Controls }\end{array}$ & 110 & 8 & 102 & \\
\hline
\end{tabular}

*Significant.

Anticardiolipin anti body isotypes $\operatorname{IgG}, \operatorname{IgM}$ and $\operatorname{IgA}$ play a key role in the pathogenesis of antiphospholipid syndrome. The IgG isotype appears to be more closely associated with clinical manifestations than either the $\operatorname{IgM}$ or $\operatorname{Ig} \mathrm{A}$ isotype. The $\mathrm{IgG}$ isotype positivity in pregnant women with $\mathrm{BOH}$ was statistically significant when compared with healthy controls (Table 2).

Table 2. aCL IgG in diseased versus controls.

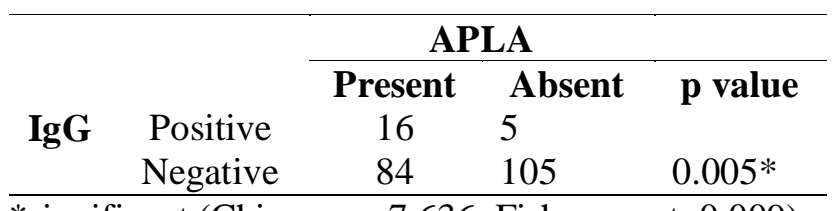

*significant (Chi-square:7.636, Fisher exact: 0.009).

The aCL antibody IgM in pregnant women with $\mathrm{BOH}$ when compared with healthy pregnant women was not statistically significant (Table 3 ).

Moderate titers (20-80 GPL or MPL units) and high titers (> 80 GPL or MPL units) of anticardiolipin antibodies have definite association with antiphospholipid syndrome. The titer of $\operatorname{IgG}$ and $\operatorname{IgM}$ anticardiolipin antibody in pregnant women with $\mathrm{BOH}$ was categorized as high, moderate and low (Table 4).

A large proportion of patients had high and moderate titers and a few had low titer CL.

Table 3. aCL IgM positivity in diseased versus controls.

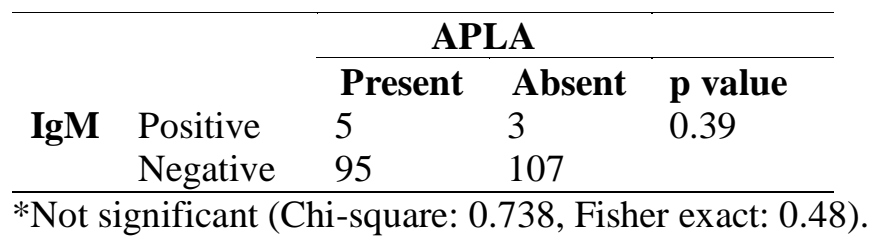

Table 4. aCL IgG and IgM titers among diseased (n: 21).

\begin{tabular}{lccc}
\hline Iso type & $\begin{array}{c}\text { High } \\
(\boldsymbol{\%})\end{array}$ & $\begin{array}{c}\text { Moderate } \\
(\boldsymbol{\%})\end{array}$ & $\begin{array}{c}\text { Low } \\
(\boldsymbol{\%})\end{array}$ \\
\hline IgG & $10(47.62)$ & $4(19.05)$ & $2(9.52)$ \\
IgM & $2(40)$ & $2(40)$ & $1(20)$ \\
Total & $12(57.14)$ & $6(28.57)$ & $3(14.28)$ \\
\hline
\end{tabular}

\section{Discussion}

Primary APS is the commonest cause of acquired thrombophilia and leads to deep veins thrombosis either with or without pulmonary embolism in $15 \%-20 \%$ of individuals, young strokes in one third and habitual abortions and still birth in $10 \%-15 \%$ of pregnant women (8). APS secondary to SLE is implicated in thromboembolic disorders and bad obstetric history in a large proportion of patients. In SLE $30 \%$ to $40 \%$ of patients produce antiphospholipid antibodies and $10 \%$ to $15 \%$ present with the clinical manifestations of antiphospholipid syndrome (9).

In a small proportion of healthy individuals, antiphospholipid antibodies were found to be positive. Though infectious diseases like syphilis, acquired immunodeficiency syndrome and others produce antiphospholipid antibodies, they do not incite clinical APS. Similarly some drugs induce a PLs production but do not cause antiphospholipid syndrome. As per the earlier studies, the first episode of stroke, coronary artery disease and venous thrombosis depends upon the presence of antiphospholipid antibodies (10). 
In pregnant women with APS, abortions occur usually after 10 weeks gestation and sometimes earlier than 10 weeks. Pregnancy losses in pre-embryonic or embryonic period is attributed to genetic and chromosomal defects in most of the cases. The course of pregnancy is uneventful until second trimester in some pregnant women with APS. After second trimester, intrauterine growth retardation occurs and leads to oligo hydramnios. Some patients land up with severe, early eclampsia or HELLP (Haemolysis, Elevated liver enzymes, Low platelets) syndrome.

The role of anti-cardiolipin antibodies in bad obstetric history has been studied on animal models like mice. The mice when injected with human polyclonal or monoclonal antibodies or with murine polyclonal antibodies showed fetal resorption and small sized offsprings. The most important hypothesis on pregnancy loss in antiphospholipid syndrome is displacement of Annexin V proteinsfrom trophoblast surface by antiphospholipids. Annexin proteins are strong anticoagulants and the displacement of these proteins make the trophoblast surfaces procoagulant. This leads to placental infarcts which in turn cause abortions or still births (11). The in vitro studies on the effects of antiphospholipid revealed impairment of trophoblastic invasion and production of human chorionic gonadotrophins thereby causing abortions, still births and also uteroplacental apoplexy (12) The predictive factors in the development of clinical syndrome are antibody level, isotype and many other unspecified properties of antiphospholipids. The risk of developing complications due to antiphospholipid antibodies in pregnancy is difficult to assert. But a previous bad obstetric history, history of thrombosis and triple positivity for lupus anticoagulant, anticardiolipin and anti- $\beta 2$ glycoprotein antibodies are the high risk factors $(13,14)$.

The anticardiolipin antibody assay by ELISA technique is a simple and highly sensitive method which helps in the diagnosis of APS. The microtiter plate wells are coated with the antigen cardiolipin or other phospholipids. In our study, cardiolipin coated plates were used. Earlier studies by Nesher et al., have shown that a small portion of patients with $\mathrm{BOH}$ were IgA aCL positive ${ }^{(15)}$. In our study IgA aCL was not done since we could not afford to procure the kit.
In the present study $21 \%$ of pregnant women with $\mathrm{BOH}$ were aCL antibodies positive. According to Stephenson, $20 \%$ of women with history of recurrent consecutive pregnancy losses were aCL positive (16). The finding is our study coincides with the above study.

The distribution of aCL IgG among pregnant women with $\mathrm{BOH}$ was high and statistically significant when compared to the isotype IgM in our study. Earlier studies by Levin et al have revealed IgG isotype was closely related to clinical feature of APS than IgM or IgA isotype (17). The present study is comparable with the above.

In our study aCL IgM was detected in $23.80 \%$ of pregnant women with $\mathrm{BOH}$. Moderate and high titer $\mathrm{CL}$ were detected in $28.57 \%$ and $57.14 \%$ of pregnant women with $\mathrm{BOH}$ respectively. However, $14.28 \%$ with low titer CL presented with $\mathrm{BOH}$. This is in contrary to the statement, a low titer CL of any isotype is less commonly associated with fetal losses (18).

Therapeutic intervention with anticoagulants heparin and low dose aspirin in aCL positive pregnant women with $\mathrm{BOH}$ improved the fetal outcome from $50 \%$ to $80 \%$ in the studies conducted by Rai and Kuttch (19).

\section{Limitations of the study}

As it is a Tertiary Care Centre, patients from all over the state and neighboring states are referred for APS screening. The resources are limited compared to turnover of patients. Hence ELISA test for aCL IgG and IgM could not be repeated after 12 weeks. Likewise aCL IgA was not done due to resources constraint.

\section{Conclusion}

One of the causes for recurrent pregnancy loss is Antiphospholipid syndrome. As there is a positive correlation between aCL IgG and $\mathrm{BOH}$ in our study, screening for APS by aCL ELISA can increase fetal survival by initiating early anticoagulant therapy when other causes for $\mathrm{BOH}$ are excluded.

\section{References}

1. Miyakis $\mathrm{S}$, Lockshin MD, Atsumi $\mathrm{T}$, et al. International consensus statement on an update of the classification criteria for definite antiphospholipid syndrome (APS). J Thromb Haemost 2006;4:295-306.

2. Rheumatology Marc C. Hochberg, Alan J. Silman, Josef 
S.Smolen, Michael E.Weinblatt, Michael H.Weisman VI edition, Elsevier, volume 2, chapter 139:1144.

3. Wilson W A, Gharavi AE, Koike T., International consensus statement on preliminary classification for definite Antiphospholipid syndrome. Arthritis Rheum 1999;42:13091311.

4. Harris EN. Special report. The second International Anticardiolipin standardization workshop 1 the kingston Antiphospholipid Antibody study (KAPS) group. Am J Clin Pathol 1990; 94(4): 476-484.

5. Pierangeli SS, Harris EN. Clinical laboratory testing for the antiphospholipid syndrome. Clin Chim Acta 2005;357:17-33.

6. Kelley's Textbook of Rheumatology, Eleviers Saunders, Vol II, 9th edition, 2013: P:1332.

7. Harris EN, Gharavi AE, Patel S, Hughes GRV. Evaluation of the anticardiolipin antibody test: report of an International workshop held 4 April 1986. Clin Exp Immunol 1987;68:215222.

8. Ginsburg KS, Liang $\mathrm{MH}$, Newcomer I, Anticardiolipin antibodies and the risk for ischemic stroke and venous thrombosis. Ann intem Med 1992;117:997-1002.

9. Levine JS, Branch DW, Rauch J. The antiphospholipid syndrome. N Engl J Med 2002;346:752-763.

10. Brey RL, Abbott RD, Cub JD, et $\beta 2$-glycoprotein-dependent anticordiolipin antibodies and risk of ischemic stroke and myocardial infarction; the Honolulu Heart Programme Stroke, 2001;32;1701-1706.

11. Rand J H. Antiphospholipid antibody mediated disruption of Annexin V antithrombotic shield: a thrombogenic mechanism for the Antiphospholipid syndrome. J Autoimmune 2000:15:107-111.

12. Di Simone N, Raschi E, TestoniC,. pathogenic role of antibeta 2-glycoprotein I antibodies in antiphospholipid associated fetal loss: characterization of beta 2-glycoprotein I binding to trophoblast cells and functional effects of anti-beta 2glycoprotein I antibodies in vitro. Ann Rheum Dis 2005;64: 462467.

13. Danza A, Ruiz-Irastorza G, Khamashta M. Antiphospholipid syndrome in obstetrics. Best Pract Res Clin Obstet Gynaecol 2012;26:65-76.

14. Ruffatti A, Calligaro A, Hoxha A, et al. Laboratory and clinical features of pregnant women with antiphospholipid syndrome and neonatal outcome. Arthritis Care Res 2010;62:302-307.

15. Nesher G, Rosenman D, Abraham AS. Valvulardystfunction in Antiphospholipid syndrome; prevalence, clinical features and treatment, Semin Arthritis, Rhem 1997:27:27-35.

16. Levine SR, Salowich-Palm L, Sawaya KL, IgG anticardiolipin antibody titer $>40 \mathrm{GPL}$ and the risk of subsequent thrombo-occlusive events and death. A prospective cohort study. Stroke 1997;28:1660-1665.

17. Rheumatology Marc C. Hochberg, Alan J.Silman, Josef S.Smolen, Michael E.Weinblatt, Michael H.Weisman VI edition, Elsevier, volume 2, chapter 139:1146.

18. Stephenson MD: Frequency of factors associated with habitual abortion in 197 couples. Fertil Steril 1996;66:24-29.
19. Kuttch NH. Antiphospholipid antibody-associated recurrent pregnancy loss: Treatment with heparin and low dose aspirin is superior to low dose aspirin alone. Am J Obstet Gynecol 1996;174:1584-1589.

Submit your next manuscript to the JICM and take full advantage of:

- Convenient online submission,

- Thorough peer review, Fast Response,

- No charges,

- Immediate publication on acceptance,

- Inclusion in Scopemed and High quality indexes,

- Research which is freely available for redistribution of the worldwide literature

To submit your manuscript, click on $h t t p: / / w w w . j i a c m . c o m$

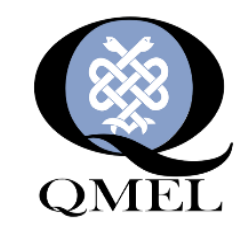

Medicine \& Publishing

Published by The ${ }^{\circledR}$ QMEL.org

Medicine \& Education \& Library

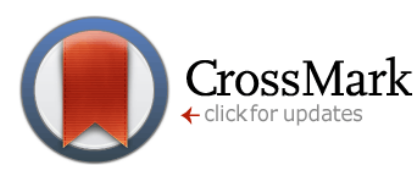

